\title{
Progress in high-speed train technology around the world
}

\author{
Li ZHOU ${ }^{1}$, Zhiyun SHEN ${ }^{2 *}$ \\ 1. Transport Bureau, The Ministry of Railways of China, Beijing 100084, China \\ 2. Traction Power State Key Laboratory, Southwest Jiaotong University, Chengdu 610031, China
}

\begin{abstract}
This is a review of high-speed train development in the sense of technology advances all over the world. Three generations of high-speed trains are classified according to their technical characteristics and maximum operating speed. Emphasis is given to the newly developed high-speed train in China, CRH380. The theoretical foundations and future development of CRH380 are briefly discussed.
\end{abstract}

Key words: high-speed railway; high-speed train technology; maximum operating speed; vehicle system dynamics; service reliability

C 2011 JMT. All rights reserved.

\section{Introduction}

$\mathrm{H}$ igh-speed trains, designed for rapidity, efficiency, energy conservation, security and comfort, give vitality to the traditional railway transportation. Railway transportation has entered into the era of high speed.

High-speed trains, a hot topic among all transportation patterns, produce considerable social and economical benifits. High speed, on the other hand, means more dynamic actions and potential danger. Any transportation mode has speed limit, which is closely linked to the technical conditions of the time. For example, the travel speed of cars was able to double only when the high-speed highway systems appeared. Similarly, a plane can reach the speed of $1000 \mathrm{~km} / \mathrm{h}$, only when it flys 10000 meters above the sea level. In Octerber 1964, in Japan, the first high-speed railway line in the world was put into operation, and the surpluses of Japanese Railway Ministry increased right in that year. Since then, the high-speed railway has experienced prosperous development.

It is convenient to classify the high-speed train technologies according to the maximum operation speed. If a train with a maximum speed nearly $250 \mathrm{~km} / \mathrm{h}$ belongs to the 1 st generation of high-speed technology; then that of $300 \mathrm{~km} / \mathrm{h}$ and $350 \mathrm{~km} / \mathrm{h}$ can be classified as the 2 nd and 3rd generations. From this perspective, Japan spent about 30 years in the 1 st generation, and 16 years in the 2nd. France spent 20 and 10 years, Germany

Received Dec. 7, 2010; revision accepted Jan. 22, 2011 *Corresponding author. E-mail: zyshen@home.swjtu.edu.cn (Z.Y. SHEN)

doi: 10.3969/j.issn.2095-087X.2011.01.001 spent 12 and 8 years in the 1st and 2nd generations, respectively. To design the 3 rd generation trains, i.e. raise the maximum speed as high as $350 \mathrm{~km} / \mathrm{h}$ or higher, has been a worldwide trend in developing high-speed train technology. But by 2008 none of contries has succeeded.

47 years ago, Japanese created the first miracle in the history of high-speed train technology, a high speed of $210 \mathrm{~km} / \mathrm{h}$ in the commercial operation of rail train system. China started to develop the high speed-train system in a quite late year, in 2007. However, the progress is very remarkable; only taking about 5 years, it has reached the world class level in the 1st and 2 nd generations of high-speed train technology, and successfully developed and commercially operated the new type of high-speed train CRH380 with the maximum speed of $350-380 \mathrm{~km} / \mathrm{h}$, being another miracle in the history of high-speed train field.

The purpose of this paper is to describe footmarks of technology development of high-speed trains aroud the world and try to explain the reason why China rapidly surpasses other contries in the development of highspeed trains.

\section{Development of high-speed train technology around the world}

\subsection{Japan}

On 4th Octerber 1964, the first high-speed railway, Tokaido Shinkansen, opened to commercial operation with the highest speed of $210 \mathrm{~km} / \mathrm{h}$. It was so successful that it brought great benifits to the company and 
returned all the investments within 7 years. Therefore many Shinkansens, like Sanyo, Tohoku, Joetsu, etc. were built up afterwards, and made the total length of Japan's high-speed rails up to $2139 \mathrm{~km}$ at present.

As Japan is a mountainous country, its rails have many curves. The minimum curve radius of the first high-speed rail was originally set as $2500 \mathrm{~m}$. It was proved to be too small and were increased to $4500 \mathrm{~m}$. But for the operation speed of more than $300 \mathrm{~km} / \mathrm{h}$, the morden high-speed rail should have the minimum curve radius above $7000 \mathrm{~m}$, preferablely $10000 \mathrm{~m}$. Besides, the section area of the tunnels on Japanese Shinkansens is $64 \mathrm{~m}^{2}$, which is also too small in comparison with the $100 \mathrm{~m}^{2}$ of the morden ones. The track conditions in Japan greatly restrict the maximum operation speed of the high-speed train. Within more than thirty years, Japan developed many new trains, like S-0, S-100, S$300, \mathrm{E}-1, \mathrm{E}-2$, etc., and took great efforts in raising the speed, but none of them can reach the highest speed of more than $270 \mathrm{~km} / \mathrm{h}$. Thus, these trains can only be classified as high-speed trains with the first generation techmology. Later, great efforts were made to the test train WIN500 for raising speeds higher than $270 \mathrm{~km} / \mathrm{h}$. At last, in 1998, with the help of test results of WIN500, a new type of high-speed train S-500 can operate at speeds up to $300 \mathrm{~km} / \mathrm{h}$ on the $393 \mathrm{~km}$ track from Hakata to Okayama on Sanyo Shinkansen. This marks the Japanese high-speed train technology stepped into the era of the 2nd generation.

At the beginning of the new century, a third tide of devoloping the high-speed train technology is to raise the operating speed to more than $350 \mathrm{~km} / \mathrm{h}$. To this end, the Japanese Shinkansen launched a program called Fastech360. After several years' study, it was concluded that under existing track conditions, the highest target speed should be reduced to $320 \mathrm{~km} / \mathrm{h}$. The train, E-5, created from this program, will be put into operation at this speed in 2011. It will be the highest operation speed in Japan, but not the one as expected for 3rd generation technology (see Table 1).

\subsection{France}

The second country that successfully developed the high-speed rail is France, who built up the first line from Paris to Lyon, TGV-PSE, in 1981, 17 years after Japan. Then in 1989 and 1994 it completed TGV-A and TGV$\mathrm{N}$. According to the above classification, these trains of $280 \mathrm{~km} / \mathrm{h}$ and $300 \mathrm{~km} / \mathrm{h}$ belong to the technology of first generarion. The second generation trains appeared 20 years later on the line TGV-Mediterranee from Valence to Marseille with upgraded infrastructure. Then, in 2007, the new high-speed line TGV-EST from Paris to Strasbourg was completed. Both lines provided better conditions for train running, and the maximum operation speed of TGV-Mediterranee and TGV-EST were increased to $320 \mathrm{~km} / \mathrm{h}$. As France achieved the highest speed i.e. $300 \mathrm{~km} / \mathrm{h}$, of the first generation trains, French TGV owned the highest operation speed i.e. 320 $\mathrm{km} / \mathrm{h}$, of the second generation as well. The speed of $320 \mathrm{~km} / \mathrm{h}$ had been also the highest operation speed all over the world by 2008.

In the third wave toward high speed, France realized that the centralized power system they used for the 1st and 2nd generation trains was not suitable for speeds higher than $350 \mathrm{~km} / \mathrm{h}$. Therefore they adopted Japan's distributed power system and designed their third generation high-speed train AGV360. The AGV360 was first tested on Italian high-speed track with the objective speed of $360 \mathrm{~km} / \mathrm{h}$. As for commercial operation in Italy, the highest speed has still not been higher than $300 \mathrm{~km} / \mathrm{h}$ by 2013 (Table 1 ).

Table 1 Footmarks of technology development for high-speed trains around the world

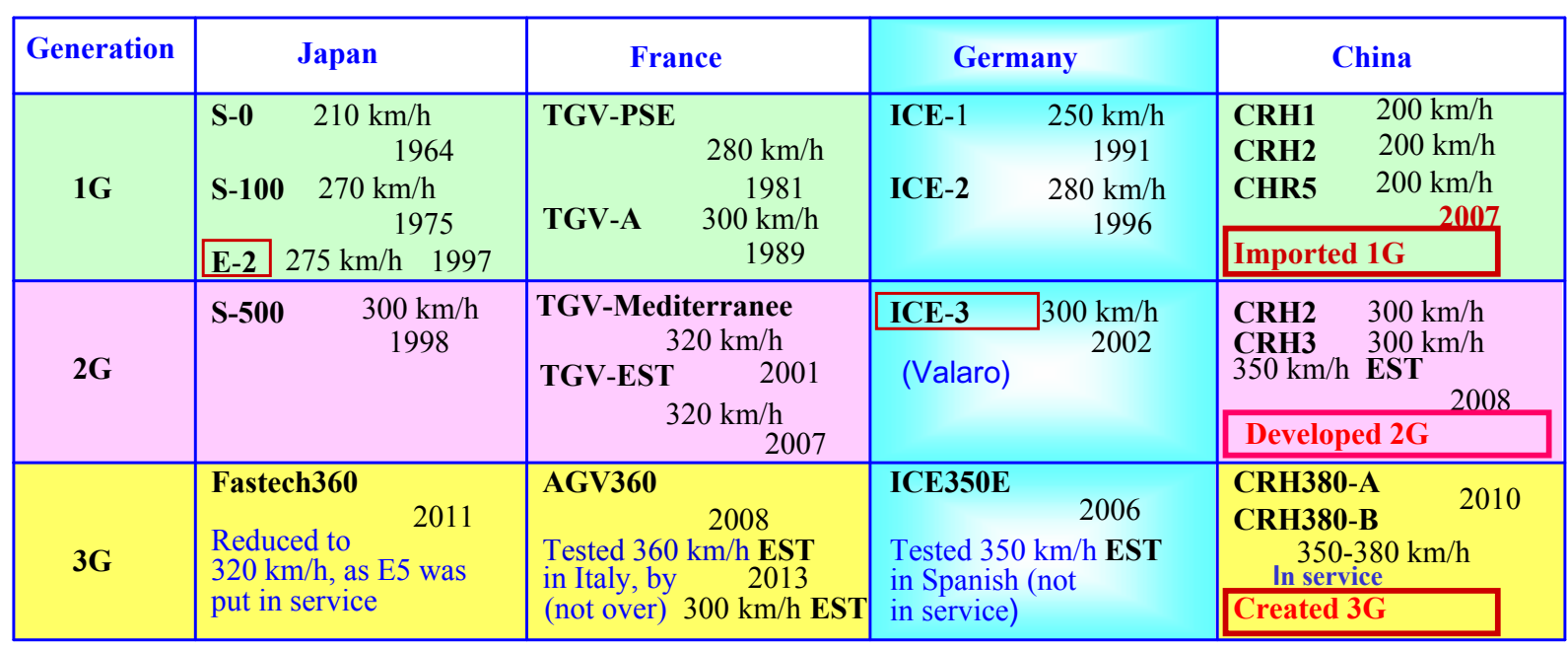




\subsection{Germany}

In Germany the train and the track are quite administratively separated. The railway construction company built the high-speed railway in segments, e.g. from Fulda to Würzburg $(1988,90 \mathrm{~km})$, from Hannover to Fulda (1991/94, $248 \mathrm{~km}$ ), from Mannheim to Stuttgart $(1985 / 91,109 \mathrm{~km})$ and from Hannover to Berlin (1998, $189 \mathrm{~km})$. In 2002 the modern "no ballast no sleeper solid concrete" track was built up between Köln and Frankfurt (197 km). Then in 2007 another segment of $98 \mathrm{~km}$ such track was laid from Nürenberg to Ingolstadt. At the same time, the German railway transport department runs the high-speed train as needed, say from Berlin to Munich, from Bonn to Berlin, etc. The trains operate at high speeds on high-speed segments, and at reduced speed on ordinary tracks. On the high-speed tracks run not only high-speed trains, but also ordinary even freight trains. This system greatly restricts the maximum speed, especially reduces the average travel speed over the whole line.

The first generation of high-speed train in Germany appeared in 1991. It is called ICE-1 with the maximum speed of $250 \mathrm{~km} / \mathrm{h}$. The next one called ICE-2 starting from 1996 with $280 \mathrm{~km} / \mathrm{h}$. Both are power centralized with technology of 1 st generation. Afterwards, Germany thus developed ICE-3 of $300 \mathrm{~km} / \mathrm{h}$ characterized as second generation technology (Table 1). But it runs at this speed only on the abovementioned two modern track segments.

As for the third generation technology in Germany, what must be mentioned is high-speed train ICE350. It was tested with a design speed of $350 \mathrm{~km} / \mathrm{h}$ on Spanish high-speed rail in 2006. But up to now, ICE350 never operated commercially in Germany. The high-speed operation on short segments helps a little in raising the average speed over the whole line.

By 2008, Span, Italy, Australia, South Korea and Taiwan district have had high-speed rails and the total length of rails in those countries, added by rails in abovementioned Japan, France and Germany, have reached $6763 \mathrm{~km}$.

\subsection{China}

On 1st August 2008, before the Beijing Olympic Games, the first high-speed railway (HSR) of $350 \mathrm{~km} / \mathrm{h}$ completed. It is from Beijing to Tianjin covering a distance of $120 \mathrm{~km}$ within $30 \mathrm{~min}$. Soon during 2009 and 2010, opened the HSRs from Wuhan to Guangzhou of $1068 \mathrm{~km}$, from Zhengzhou to Xian of $505 \mathrm{~km}$, from Shanghai to Nanjing of $317 \mathrm{~km}$ and from Shanghai to Hangzhou of $202 \mathrm{~km}$. If the lines of $250 \mathrm{~km} / \mathrm{h}$ are included, the total length of HSR consisted in $7531 \mathrm{~km}$, more than the combination of those all over the world. The longest HSR in the world, Beijing-Shanghai line, will be completed in next year, and its maximum operation speed will be $380 \mathrm{~km} / \mathrm{h}$. As it is planned, in 2012 the total length of HSR in China will reach $13000 \mathrm{~km}$, of which $8000 \mathrm{~km}$ is in $350 \mathrm{~km} / \mathrm{h}$ class, and $5000 \mathrm{~km}$ is in $250 \mathrm{~km} / \mathrm{h}$ grade. China spent less than 7 years to catch up and overtake other countries in HSR development. As Table 1 shows, China imported from other countries the first generation HSR technology, and soon upgraded it to the second generation. Without delay, the third generation technology was successfully applied. The currently most advanced high-speed train CRH380 can steadily, smoothly, safely operate at the speeds of 350$380 \mathrm{~km} / \mathrm{h}$. The rate of seats occupation is as high as $100 \%-125 \%$, which demonstrates that the passenger transportation market accepts the modern railway with full satisfaction.

\section{Characteristics and theoretical founda- tion of high-speed trains in China}

It is worth investigating why and how China can achieve such unprecedented progress in high-speed railway development. Vast transportation market is the certain factor calling for modernized railways. The technical breakthrough lies in the concept and theory of integral optimization of the vast train-track system. The maximum operation speed is the result of a series of interactions between the train and its environments. Unlike other countries whose train speeds are restricted by the existing conditions of the rail track, China's highspeed rail and train are manufactured and built in a unified way. The technical standards and parameters are determined by the integral optimization of the vast system containing the train and all the related factors.

The China's high-speed train CRH380 shows extraordinary good dynamic performances in operation. According to recent field tests, at $486.1 \mathrm{~km} / \mathrm{h}$, the derailment coefficient is only 0.2 against the security norm of 0.8 , the ride quality indexes are 1.8 and 2.0 against the standards of 2.0 and 2.5 in lateral and vertical directions, respectively. The emergency brake distance at $350 \mathrm{~km} / \mathrm{h}$ is $5908 \mathrm{~m}$ against the required of $6500 \mathrm{~m}$. A new point of view about speed increase is to achieve the best compatibility between the train and all factors around it. The model for the whole system is shown in Fig. 1. Among them, the interaction between wheel and rail is the most important dynamic pair. Then, the pantograph and catenary interaction follows. For high-speed train system, the aerodynamic action also needs careful consideration. 


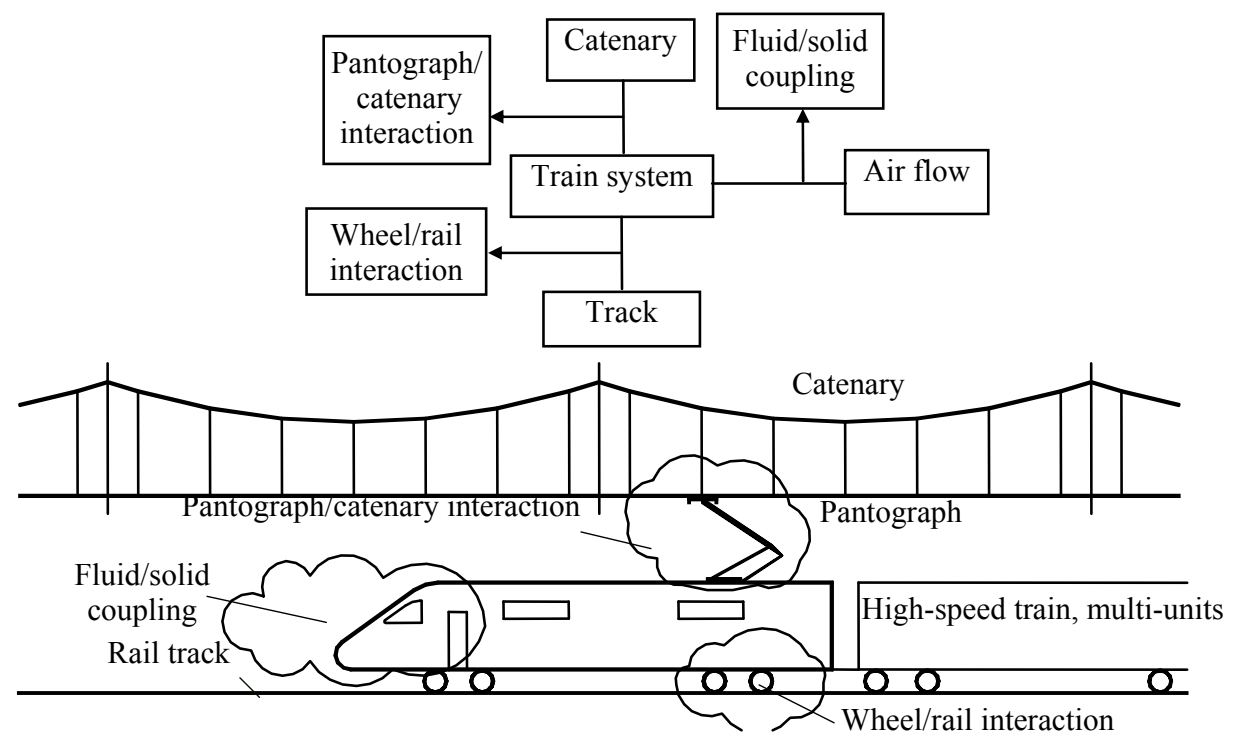

Fig. 1 System modeling of train coupling with environment

Fig. 2 shows the architecture of this vast system. It not only provides the parameters for the train structure, but also for the infrastructure and the catenaries. The aerodynamics analysis is used for streamlined shape, aero dynamical drag, noise, and the stress and strain of the car structure caused by aero dynamic actions. To evaluate the dynamic stability and responses of the train system, all factors in Fig. 2 must be considered. According to the simulation and optimization results, the parameters and the technological standards can then be decided. To exactly implement these standards through all the engineering and manufacturing processes of train
CRH380, six work groups were set up, i.e. track survey and design, infrastructure construction, train design and manufacturing, control and communication system, comprehensive integration, and management and administration. These groups are organized under the unified leadership. Scientifically expounded and proved technical standards were exactly implemented and strictly controlled in each link of the track building and train manufacturing procedure. This should be the real reason of the miracle performed by China's high-speed railway.

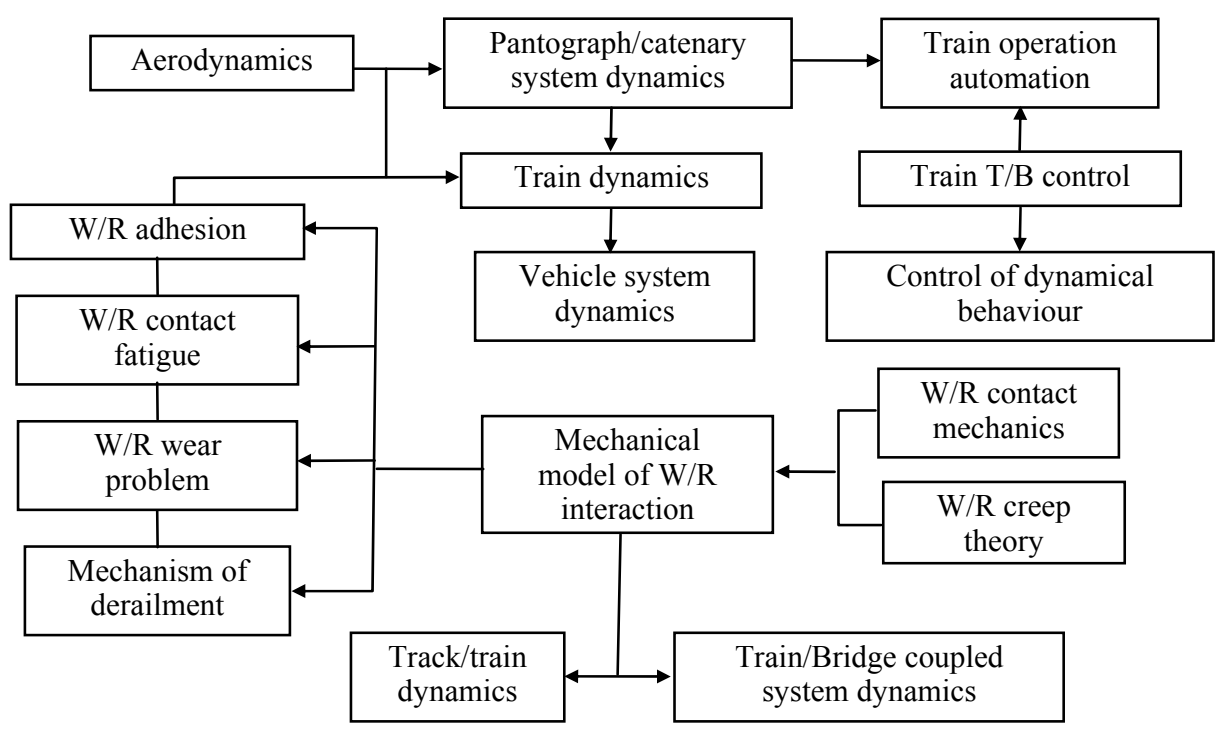

Fig. 2 The architecture of vehicle system dynamics 


\section{All process engineering for high-speed trains in China}

As a passenger transportation means, the high-speed trains should garanttee absolute safety and high quality service during operation. For this purpose, the all process engineering science is used to set up a control system to monitor the whole life of each train individuly.

The first step is to set up a criterion, i.e. the service reliability of the high-speed train system (see Fig. 3). It consists of two parts, the comprehensive ride quality and the derailment security domain. Any factor related to the comfort of passengers in the car will be included in the comprehensive ride quality. According to the existed standards, only the vertical and lateral ride indices are considered. The italic items in the first bracket of Fig. 3 have to be included as well.

Not-to-derail is the fundamental requirement in train operation. At present, only a few critera, e.g. the derailment coefficient, axel load reduction and jump time above rail (Fig. 3), are used to determine the critical conditions of this crucial accident. It is rational to allocate derailment security as a domain surrounded by many boundaries, beyond which the train must not be operated. These boundaries are listed in the 2nd bracket in Fig. 3. The service reliability is measured by numerical indices obtained from the dynamic responses in train service. Fig. 4 shows the simulation of the coupled train-track system.

$$
\text { High-speed train }\left\{\begin{array}{l}
\text { ride quality } \\
\text { system reliability }\left\{\begin{array}{l}
\text { Vertical ride index } \\
\text { Lateral ride index } \\
\text { V/L ride index } \\
\text { Centrifugal } \\
\text { Start/brake acceleration permitted } \\
\text { Noise } \\
\text { Air conditioning } \\
\text { Man-machine engineering }
\end{array}\right. \\
\text { Security domain } \\
\text { Derailment coefficient Q/V } \\
\text { Load reduction } \\
\text { Jump time above rails } \\
\text { Material fracture } \\
\text { Fretting fracture } \\
\text { Earthquake or bad weather } \\
\text { Foreign body on track } \\
\text { Miss operation of the driver } \\
\text { Miss train control }
\end{array}\right.
$$

Fig. 3 Service reliability of the train system

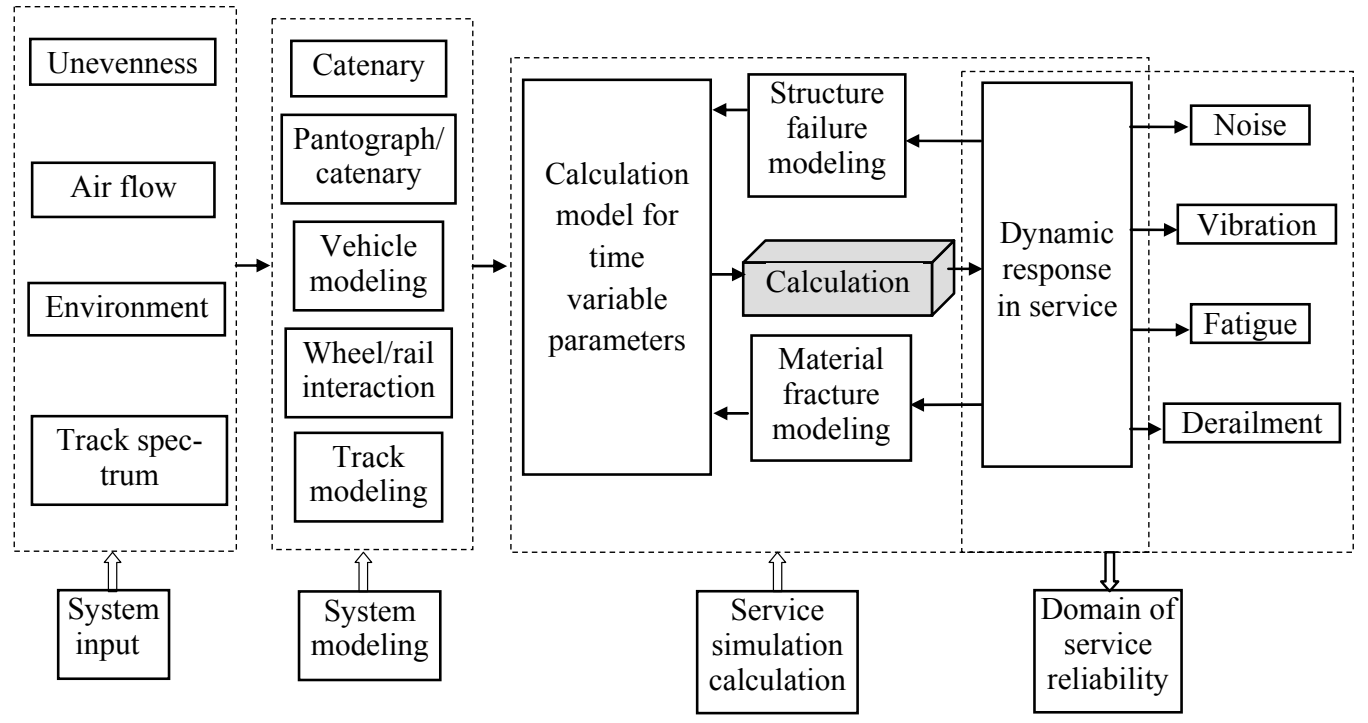

Fig. 4 Computer simulation of service reliability for high-speed trains 
The parameters in Fig. 4 are varying over time. Since Wuhan-Guangdong high-speed railway operation, a 3year research program has been run to measure the variations of parameters in service, e.g. the conicity of the rail head and wheel tread, the parameters of suspension, the response accelerations etc. The continuous measurements of three assigned trains have been proceeding along the $1068 \mathrm{~km}$ track. From the collected data, the rule of parameters' variation over time can be observed and the time-variable vehicle system can be simulated.

To calculate service reliability index, the variations of parameters must be known in real time. Thousands of transducers were laid on the train, to form a sensor unit. The wireless communication system transmits the data to the control center for processing. By cloud computation, the service index of the train operation is calculated and returned in real time to the control panel giving instructions for reliable service of the train. This is a big program that spends years to complete.

The indices of service reliability are not only good indications of train operation, but also usable in redesign and re-manufacturing of the high-speed trains (see Fig. 5).

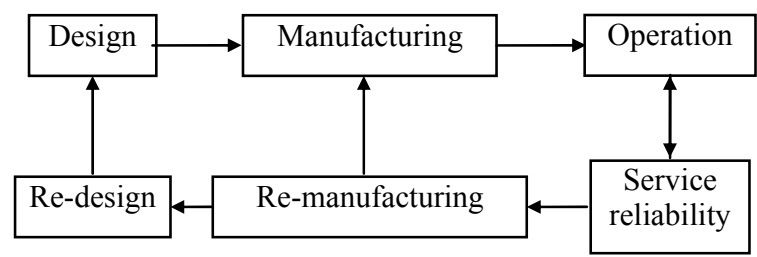

Fig. 5 All process engineering of high-speed trains

\section{Ending remarks}

(1) High-speed railways have shown vigorous vitality in modern transportation. The pursuit of higher operation speed of trains is a trend across the world.

(2) The maximum speed of high-speed trains in commercial operation is a reflection of various interactions between the train and the surrounding environments. So, it can be regarded as the most important indicator in the classification of the high-speed train technologies, e.g. about $250 \mathrm{~km} / \mathrm{h}$ as the first generation, $300 \mathrm{~km} / \mathrm{h}$, the second and $350 \mathrm{~km} / \mathrm{h}$, the third one.

(3) At the beginning of the 21 st century, many highspeed train makers around the world tried to raise the maximum operation speed above $350 \mathrm{~km} / \mathrm{h}$. Up to present, only the China's CRH380 succeeded in commercial operation with speed more than $350 \mathrm{~km} / \mathrm{h}$. The rea- son of its success is that China found the optimal compatibility between the train and its dynamical environments, basically between the train and the track. This experience speeds up the progress in development of the high-speed train technology of the third generation in other countries.

\section{References}

[1] T. Takatsu, The history and future of high-speed railways in Japan, Japan Railway and Transport Review, 2007(48): 6-21.

[2] UIC High Speed, Necessities for future high speed rolling stock, 2010.

[3] R. Takagi, High speed railways: the last 10 years, Japan Railway and Transport Review, 2005(48): 22-29.

[4] M. Givoni, Development and impact of the modern highspeed train: a review, Transport Reviews, 2006, 26(5): 593-611.

[5] J. Campos, G. de Rus, Some stylized facts about high speed rail: a review of HSR experiences around the world, Transport Policy, 2009, 16(1): 19-26.

[6] K. Ebeling, High speed railways in Germany, Japan Railway and Transport Review, 2005(40): 36-45.

[7] C. Rozycki, H. Koeser, Ecology profile of the German high speed rail passenger transport system, ICE, The International Life Cycle Assessment, 2003, 8(2): 83-91.

[8] UIC, High speed rails leading asset for customers and society, Paris: UIC Publications, 2005.

[9] J. Campos, R. de Gines, B. Ignacio, A review of HSR experiences around the world, Munich: MPRA Paper, 2008.

[10] S.D. Gleave, High speed rail: international comparisons, London: Commission for Integrated Transport, 2004.

[11] UIC, Railway time-series data, 1970-2004, Paris: UIC Publications, 2006.

[12] S.G. Zhang, The Fundamental Theory and Engineering Technique of High-Speed Train, Beijing: Science Publisher, 2007 (in Chinese).

[13] S.G. Zhang, A Study of High-Speed Train Design, Beijing: Railway Publisher, 2009 (in Chinese).

[14] W.H. Zhang, S.G. Zhang, High-speed train vast system dynamics and service reliability simulation, Journal of Southwest Jiaotong University, 2008, 43(2): 143-153 (in Chinese).

[15] H. Suzuki, Research trends on riding comfort evaluation in Japan, Journal of Rail and Rapid Transit, 1998, 212(1): 61-72.

[16] W.M. Zhai, Track-Train Coupled Dynamics, 3rd edition, Beijing: Science Pulisher, 2007 (in Chinese).

[17] W.H. Zhang, Vehicle Dynamic Simulation, Beijing: Railway Publisher (in Chinese).

(Editor: Yao ZHOU) 